\title{
Stroke and diabetes: a dangerous liaison
}

\author{
SARAH L MACPHERSON, ${ }^{1}$ CHRISTOPHER R SAINSBURY, ${ }^{1}$ JESSE DAWSON, ${ }^{2}$ GREGORY C JONES ${ }^{1}$
}

\begin{abstract}
Ischaemic stroke is a major cause of disability and death and the incidence rate of ischaemic stroke is doubled in patients who have diabetes. Admission hyperglycaemia in acute stroke patients is associated with higher mortality, longer hospital stay and worse functional outcome. However, it remains unclear whether hyperglycaemia is in fact a marker of stroke severity or whether hyperglycaemia directly contributes to brain damage. Potential mechanisms of hyperglycaemia related brain damage in stroke include acidosis, oxidative stress and reperfusion injury. Evidence suggests a potential benefit of treatment of hyperglycaemia with insulin in acute stroke patients but the potential for morbidity caused hypoglycaemia should be considered. The American Heart Association/American Stroke Association guidelines recommend maintaining the blood glucose level in the range 7.8-10 $\mathrm{mmol} / \mathrm{L}$ during acute stroke hospitalisation whilst the European Stroke Organization guideline recommends lowering the blood glucose with insulin to below $10 \mathrm{mmol} / \mathrm{L}$. More research is needed to explore the impact of admission hyperglycaemia and hypoglycaemia on stroke outcomes and the role of other glucose lowering therapies. Br J Diabetes 2016;16:114-118
\end{abstract}

Key words: hyperglycaemia, hypoglycaemia, diabetes, ischaemic, haemorrhagic, stroke, mortality, outcomes, insulin

\section{Introduction}

Ischaemic stroke is a major cause of disability and is now the 4th leading cause of death in the USA. ' Stroke accounted for 5.7 million deaths in 2005 worldwide, with the incidence rate of ischaemic stroke approximately doubled in patients who have diabetes. ${ }^{2}$ Approximately one-third of patients with transient ischaemic attacks or ischaemic stroke who have no previous history of diabetes have prediabetes and over a quarter have newly

Department of Diabetes and Endocrinology, Gartnavel General Hospital, Glasgow, UK

2 College of Medical, Veterinary and Life Sciences, Institute of Cardiovascular and Medical Sciences, University of Glasgow, Queen

Elizabeth University Hospital, Glasgow, UK

Address for correspondence: Dr Gregory C Jones

Department of Diabetes, Gartnavel General Hospital, 1053 Great

Western Road, Glasgow, G12 OYN, UK

Tel: +44 (0)1412113259

E-mail: g.jones3@nhs.net

http://dx.doi.org/10.15277/bjd.2016.089 diagnosed diabetes. ${ }^{3}$ A prospective study of over 13,000 people showed that, in people with type 2 diabetes, the risk of death from myocardial infarction and stroke is increased two fold, independent of other known cardiovascular risk factors. ${ }^{4}$ Thus, diabetes increases the risk of stroke and the risk of death from stroke.

The definition of hyperglycaemia varies in stroke studies and ranges from $6.1 \mathrm{mmol} / \mathrm{L}$ to $>10 \mathrm{mmol} / \mathrm{L}$ glucose. Based on these definitions, hyperglycaemia is found at presentation in 30-60\% of all stroke patients. ${ }^{5}$ Research has shown that acute hyperglycaemia in stroke contributes to worse functional outcomes, longer hospital admission and higher mortality. ${ }^{6}$ There is uncertainty about what level of blood glucose contributes to unfavourable outcomes. Evidence varies regarding whether there is a glucose threshold for worse outcomes or whether the relationship is linear. 7,8 One group found that the capillary glucose level with the highest predictive accuracy for poor outcome was $\geq 8.6 \mathrm{mmol} / \mathrm{L}$. ${ }^{7}$ Another group showed that odds for favourable stroke outcome decrease as admission blood glucose increases (odds ratio of neurological improvement 0.76 per $5.6 \mathrm{mmol} / \mathrm{L}$ increase in glucose). ${ }^{8}$

This literature review will explore the proposed underlying mechanisms by which alterations in blood glucose may contribute to poor outcomes, summarise both animal studies and clinical studies to date and propose topics for future research. Evidence for treatment of hyperglycaemia on admission with acute stroke will also be explored.

\section{The impact of hyperglycaemia on stroke}

Cell death occurs in ischaemic stroke due to depletion of glucose and oxygen resulting in reduced adenosine triphosphate (ATP) production. ${ }^{5}$ It is unclear exactly how hyperglycaemia causes worse outcomes in acute stroke. ${ }^{6}$ Hyperglycaemia related acidosis is a proposed mechanism. Under ischaemic conditions, lactic acid production from anaerobic metabolism contributes to an acidic $\mathrm{pH}$. Hyperglycaemia accentuates lactic acid production and reduced pH. Brain tissue $\mathrm{pH}$ can be reduced from 7.2 to 6.6 during ischaemia. Under hyperglycaemic conditions, $\mathrm{pH}$ can drop further to $<6,9$ potentially causing protein denaturation, acid sensitive ion channel activation and iron release, contributing to ischaemic brain injury. ${ }^{10,11}$

Hyperglycaemia also plays a role in oxidative stress by accelerating the production of free radicals since, glucose is the substrate for their production. ${ }^{5}$ Figure 1 summarises key mechanisms likely to be involved in mediating the adverse effects of hyperglycaemia on stroke outcomes. 


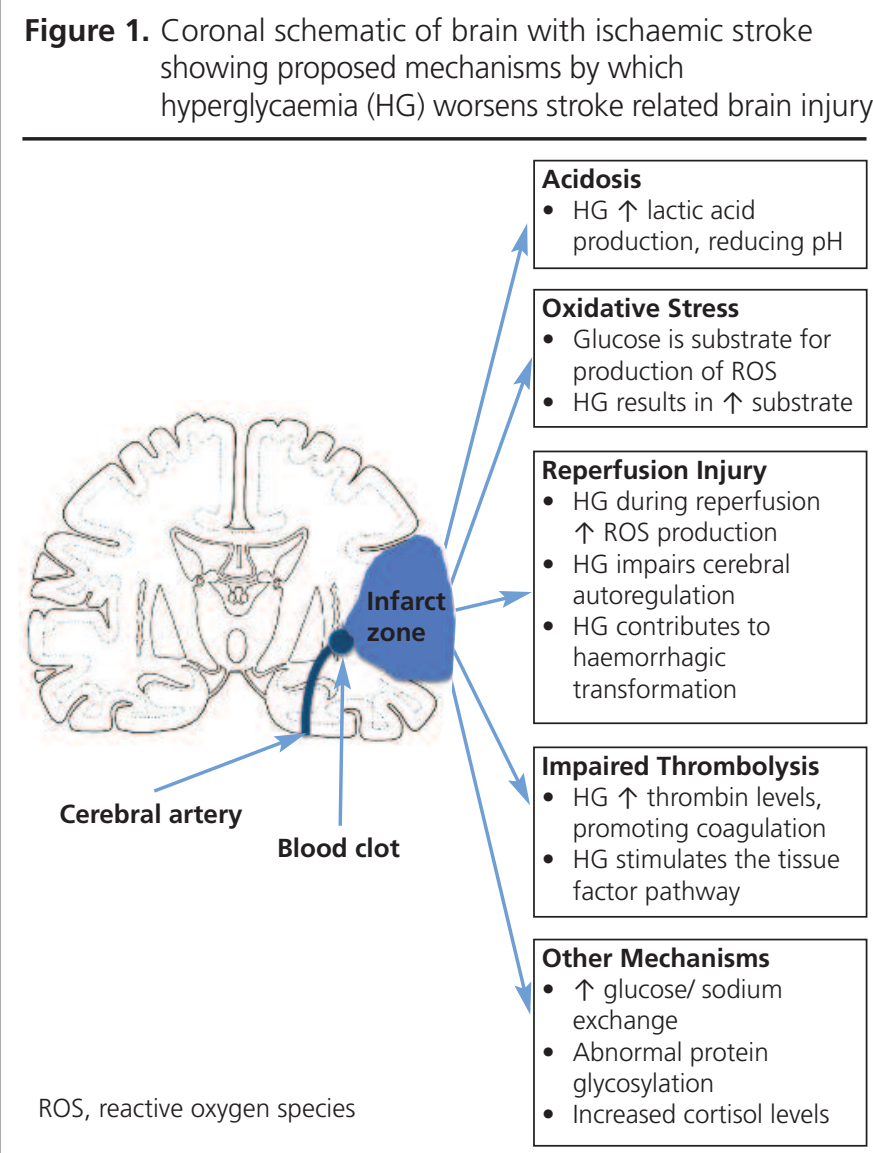

\section{Animal studies: stroke, hyperglycaemia and reperfusion injury}

A variety of studies in animals have been done to shed light on the impact of hyperglycaemia on acute stroke outcomes. Early studies found that hyperglycaemia at the time of stroke resulted in worse neuronal and vascular injury post-stroke, in keeping with clinical findings. ${ }^{12,13}$ Increased infarct size and levels of inflammatory markers were observed in hyperglycaemic Zucker obese rats. ${ }^{6}$ However, another study reported that hyperglycaemia did not affect the infarct volume but increased blood brain barrier permeability and haemorrhagic transformation. ${ }^{14}$

Studies in rats has demonstrated that larger infarcts are seen in hyperglycaemic animals in brain territories with collateral circulation compared to those in end arterial region. ${ }^{15}$ This supports studies that show lacunar stroke outcomes are not worsened by hyperglycaemia. ${ }^{16}$ These strokes affect areas with poor collateral circulation. Thus, animal studies are generally in agreement with clinical study findings that show worse outcomes with hyperglycaemia at time of acute stroke. There is disagreement on the impact on infarct size. The role of hyperglycaemia in reperfusion injury is likely to play a significant role. ${ }^{6}$ Blood flow must be restored to ischaemic brain tissue to enable survival. However, reperfusion can damage ischaemic brain further. Hyperglycaemia may worsen cerebral blood flow (CBF) after stroke. Work has shown that CBF was reduced to the ischaemic region in hyperglycaemic rats compared to controls. ${ }^{17}$
This was associated with larger infarct size and is in agreement with previous work. ${ }^{17-20}$ One study contradicts this hypothesis, possibly due to differences in hyperglycaemia severity. ${ }^{21}$

Cerebral autoregulation is the process by which the blood supply to the brain is maintained despite changes in perfusion pressure. To achieve this, smooth muscle cells constrict when perfusion pressure is high and relax when pressure is low to keep blood flow constant. ${ }^{22,23}$ Work using rats has shown that, under hyperglycaemic conditions, cerebral vessels were incapable of responding to changes in pressure, impairing cerebral autoregulation..$^{24,25}$

In addition to reperfusion injury, hyperglycaemia may also affect outcome after thrombolytic therapy for ischaemic stroke. High blood glucose levels increase coagulation by increasing thrombin production and stimulating the tissue factor pathway. Hyperglycaemia also reduces the activity of tissue plasminogen activator thrombolysis treatment by increasing production of plasminogen activator inhibitor. ${ }^{6}$

\section{Clinical studies: mortality, functional status and haemorrhagic transformation}

A strong link between admission hyperglycaemia in ischaemic and haemorrhagic stroke patients and negative outcomes has been shown. These outcome measures include infarct size, disability and mortality. ${ }^{5}$ Regression analyses controlling for other confounding factors demonstrate the importance of hyperglycaemia in negative outcomes. ${ }^{26-28}$ Recently, these findings have been supported by an imaging study. ${ }^{29}$ The authors used transcranial Doppler, MRI, and magnetic resonance spectroscopy to show that hyperglycaemia is a strong predictor of infarct growth and poor outcome. The study had a small sample size of only 47 patients but showed that the stroke lesion on diffusion weighted imaging grew 2.7 times faster in patients with hyperglycaemia treated with tissue plasminogen activator than in those without. The study was strengthened by the use of National Institutes of Health Stroke Scale scores.

A systematic review and meta-analysis was undertaken to explore stress hyperglycaemia and stroke prognosis in patients with and without diabetes. ${ }^{27}$

Twenty-six studies were included. The group found that the unadjusted relative risk of in-hospital or 30-day mortality associated with an admission glucose level of 6-8 mmol/L was 3.07 in non-diabetic patients and 1.30 in patients with diabetes for both ischaemic and haemorrhagic stroke. Thus, even a small increase in blood glucose level in non-diabetic patients with ischaemic stroke increases mortality three fold. These patients also have an increased risk of poor functional recovery compared to patients with lower blood glucose. This outcome is consistent with studies showing that mean admission blood glucose is higher in non-survivors of stroke than survivors. ${ }^{27-30}$ Furthermore, another study showed that an admission blood glucose of $8 \mathrm{mmol} / \mathrm{L}$ or greater was an independent predictor of death, symptomatic intracranial haemorrhage and poor functional status at 90 days in thrombolysed patients..$^{31}$ Of patients with an admission glucose of less than $8 \mathrm{mmol} / \mathrm{L}, 40 \%$ had an excellent functional outcome, compared with $27.7 \%$ of those with a glucose of greater than $8 \mathrm{mmol} / \mathrm{L}^{3}$ 
$30.8 \%$ of patients with an admission glucose of greater than $8 \mathrm{mmol} / \mathrm{L}$ died, compared with $18.7 \%$ of patients with an admission glucose of less than $8 \mathrm{mmol} / \mathrm{L} .{ }^{31}$ Strengths of this study include the large sample size of 1,098 patients, the use of prospective data from multiple centres and assessment of outcomes at 90 days. It would also have been useful to study the impact of hyperglycaemia in the longer term over years following stroke.

Hyperglycaemia could disrupt the blood brain barrier and promote development of haemorrhage. Two human studies investigated this. 32,33 One study showed that admission blood glucose levels of $>8.4 \mathrm{mmol} / \mathrm{L}$ resulted in increased risk of conversion to haemorrhagic stroke compared with lower blood glucose. ${ }^{32}$ On the contrary, the admission blood glucose level did not affect the risk of haemorrhagic infarct conversion in 1,259 patients with ischaemic stroke participating in a randomised, placebo-controlled evaluation of a low-molecular-weight heparinoid. ${ }^{33}$

\section{Treatment of hyperglycaemia with insulin: does it improve stroke outcomes?}

Since hyperglycaemia is associated with poor stroke outcomes, it is logical to consider whether treatment to normalise glucose levels would improve outcomes. Eleven randomised controlled trials were included in a recent Cochrane review to assess whether intensively monitoring insulin therapy to maintain serum glucose between 4 and $7.5 \mathrm{mmol} / \mathrm{L}$ in the first 24 hours of acute ischaemic stroke influences outcome. There was no difference between outcomes of death or dependency between control (792 patients) and intervention groups (791 patients). Importantly, there was an increased risk of asymptomatic hypoglycaemia in the treatment group. ${ }^{26}$ Other studies argue that the harmful effects of hyperglycaemia may be partially reversed by treatment to rapidly correct blood glucose using insulin. Grant et al found that it was beneficial to treat with insulin if patients had a blood glucose of $\geq 10.1 \mathrm{mmol} / \mathrm{L} .{ }^{34}$ Thus, treatment with insulin to treat hyperglycaemia in acute stroke patients could provide some benefit but may cause hypoglycaemia.

\section{Current clinical practice: management of blood glucose in acute stroke}

Several studies have looked at the impact of treating hyperglycaemia in critically ill patients. ${ }^{35}$ There is some evidence that treatment with insulin in critically ill patients reduced adverse outcomes such as infections and renal failure in patients with a broad range of illnesses, not necessarily stroke. ${ }^{35}$ One meta-analysis included 35 studies of critically ill patients and concluded that insulin therapy improved short term mortality. However, the results should be interpreted with caution since the results of individual studies varied. 36

The American Heart Association/American Stroke Association guidelines recommend maintaining the blood glucose level in the range $7.8-10 \mathrm{mmol} / \mathrm{L}$ during acute stroke hospitalisation. ${ }^{37}$ The European Stroke Organization guideline recommends lowering the blood glucose with insulin to below $10 \mathrm{mmol} / \mathrm{L} .^{38}$

\section{Could hyperglycaemia be a bystander in acute stroke?}

Despite some evidence supporting the role of hyperglycaemia wors-

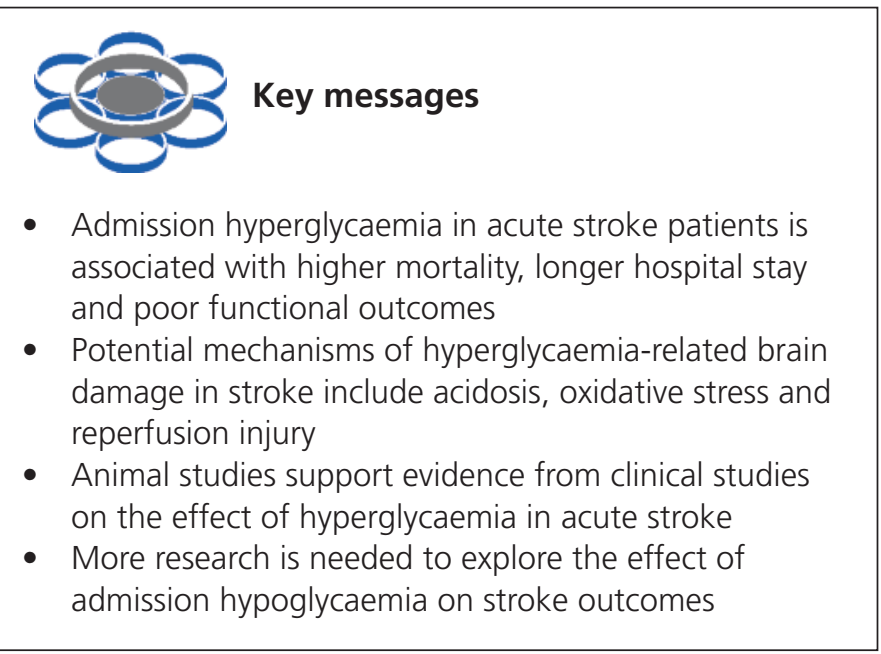

ening stroke outcomes,, 5 there is evidence to the contrary. It remains unclear whether hyperglycaemia is in fact a marker of stroke severity or whether hyperglycaemia directly contributes to brain damage. ${ }^{31}$

One study found that $\mathrm{HbA}_{1 \mathrm{c}}$ was a predictor of outcomes but that admission blood glucose was not. ${ }^{39}$ This could be due to routine treatment of hyperglycaemia with insulin in this centre. Other authors have concluded that cortisol is a better predictor of poor stroke outcomes than admission blood glucose. O'Neill et al studied the relationship between reactive hyperglycaemia, stress hormone response and outcome in 23 consecutive elderly stroke patients and found that hyperglycaemia is a predictor of outcome in stroke. ${ }^{40}$ However, when variables were analysed by logistic regression, only the cortisol concentration was related to outcome $(p=0.02)$. The group suggest that this could be due to high variation in levels of other hormones. It should be noted that the study included only small numbers and complete data were available for only 15 patients. 40

A further study included 71 subjects. ${ }^{41}$ This group found that glucose levels were higher in patients who died during the course of the study. However, when cortisol levels and age were taken into account using multivariate analysis, this relationship became insignificant. ${ }^{41}$

\section{Future research}

Hyperglycaemia has been associated with no reflow of blood and with blood-brain barrier disruption in a rat model of hyperglycaemia. ${ }^{5}$ Hyperglycaemia is associated with increased oxidative stress that can modify tight junction proteins, altering the blood brain barrier. ${ }^{6}$ Thus, it is plausible that hyperglycaemia might exert effects on cerebrovascular tone and endothelium. ${ }^{5}$ Therefore, further work to investigate possible methods of vasculoprotection may be valuable. Potential treatments to reduce ischaemic injury and enhance recovery from stroke in hypergycaemic rat models are being explored. ${ }^{6}$ Desferioxamine administration to diabetic rats with middle cerebral artery occlusion improved mortality, haemorrhagic transformation and infarct volume. ${ }^{42}$ Since treatment of hyperglycaemia with insulin is associated with a risk of hypoglycaemia, it would be prudent to consider other diabetes treatments such as 
dipeptidyl peptidase-4 inhibitors and sodium-glucose co-transporter-2 inhibitors that do not cause hypoglycaemia. There is no consensus on what level of elevated admission blood glucose affects outcomes. This also merits investigation. Compared with hyperglycaemia, there is a lack of evidence regarding the effects of hypoglycaemia on stroke outcomes. This is another area for future research.

\section{Conclusion}

The majority of research into hyperglycaemia and stroke concludes that high blood glucose levels result in higher mortality and poorer functional outcomes. Possible mechanisms of hyperglycaemia related brain damage include acidosis, oxidative stress, reperfusion injury, interference with glucose/sodium transport and glucose related cortisol increase. Elucidating the biochemical causes of hyperglycaemia related effects on stroke may provide us with new drug targets. Further investigation into the effects of use of insulin and novel therapies as treatment for acute hyperglycaemia in stroke may enable development of detailed treatment guidelines to improve patient outcomes.

\section{Conflict of interest None. \\ Funding No funding was received for this work.}

\section{References}

1. Towfighi A, Saver JL. Stroke declines from third to fourth leading cause of death in the United States. Historical perspective and challenges ahead. Stroke 2011:42:2351-5. http://dx.doi.org/10.1161/STROKEAHA.111.621904

2. Kuklina EV, Tong X, George MG et al. Epidemiology and prevention of stroke: a worldwide perspective. Expert Rev Neurother 2012;12:199208. http://dx.doi.org/10.1586/ern.11.99

3. Fonville $\mathrm{S}$, Zandbergen AA, Vermeer SE et al. Prevalence of prediabetes and newly diagnosed diabetes in patients with a transient ischemic attack or stroke. Cerebrovasc Dis 2013;36:283-9. http://dx.doi.org/10.1159/000353677

4. Almdal T, Scharling $H$, Jensen JS, Vestergaard $H$. The independent effect of type 2 diabetes mellitus on ischaemic heart disease, stroke, and death. Arch Intern Med 2004;164:1422-6. http://dx.doi.org/10.1001/archinte. 164.13.1422

5. Robbins NM, Swanson RA. Opposing effects of glucose on stroke and reperfusion injury: acidosis, oxidative stress, and energy metabolism. Stroke 2014:45:1881-6.

http://dx.doi.org/10.1161/STROKEAHA.114.004889

6. Hafez $S$, Coucha M, Bruno A et al. Hyperglycemia, acute ischemic stroke and thrombolytic therapy. Trans/ Stroke Res 2014;5:442-3. http://dx.doi.org/10.1007/s12975-014-0336-z

7. Fuentes B, Castillo J, San Jose B et al. The prognostic value of capillary glucose levels in acute stroke: the GLycemia in Acute Stroke (GLIAS) study. Stroke 2009;40:562-8. http://dx.doi.org/10.1161/STROKEAHA.108.519926

8. Bruno A, Levine SR, Frankel MR et al. Admission glucose level and clinical outcomes in the NINDS rt-PA stroke trial. Neurology 2002; 59:669-74. http://dx.doi.org/10.1212/WNL.59.5.669

9. Siemkowicz E, Hansen AJ. Brain extracellular ion composition and EEG activity following 10 minutes ischemia in normo- and hyperglycaemic rats. Stroke 1981:12:236-40. http://dx.doi.org/10.1161/01.STR.12.2.236

10. Ying W, Han SK, Miller JW et al. Acidosis potentiates oxidative neuronal death by multiple mechanisms. J Neurochem 1999;73:1549-56. http://dx.doi.org/10.1046/j.1471-4159.1999.0731549.x

11. Xiong ZG, Zhu XM, Chu XP et al. Neuroprotection in ischemia: blocking calcium-permeable acid-sensing ion channels. Cell 2004;118:687-98. http://dx.doi.org/10.1016/j.cell.2004.08.026
12. Martini SR, Kent TA. Hyperglycemia in acute ischemic stroke: a vascular perspective. I Cereb Blood Flow Metab 2007;27:435-51. http://dx.doi.org/10.1038/sj.jcbfm.9600355

13. Ergul A, Li W, Elgebaly MM et al. Hyperglycemia, diabetes and stroke: Focus onthecerebrovasculature. Vascul Pharmacol 2009;51:44-9. http://dx.doi.org/ 10.1016/j.vph.2009.02.004

14. Xing $Y$, Jiang $X$, Yang $Y$ et al. Hemorrhagic transformation induced by acute hyperglycemia in a rat model of transient focal ischemia. ActaNeurochir Supp/ 2011;111:49-54. http://dx.doi.org/10.1007/978-3-7091-0693-8_9

15. Prado R, Ginsberg MD, Dietrich WD et al. Hyperglycemia increases infarct size in collaterally perfused but not end-arterial vascular territories. J Cereb Blood Flow Metab 1988;8:186-92.

http://dx.doi.org/10.1038/jcbfm. 1988.48

16. Cipolla MJ, Godfrey JA. Effect of hyperglycemia on brain penetrating arterioles and cerebral blood flow before and after ischemia/reperfusion. Trans/ Stroke Res 2010;1:127-34.

http://dx.doi.org/10.1007/s12975-010-0014-8

17. Kawai N, Keep RF, Betz AL. Hyperglycemia and the vascular effects of cerebral ischemia. Stroke 1997;28:149-54. http://dx.doi.org/10.1161/01.STR.28.1.149

18. Nakai H, Yamamoto YL, Diksic M et al. Triple-tracer autoradiography demonstrates effects of hyperglycemia on cerebral blood flow, $\mathrm{pH}$, and glucose utilization in cerebral ischemia of rats. Stroke 1988;19:764-72. http://dx.doi.org/10.1161/01.STR.19.6.764

19. Quast MJ, Wei J, Huang NC et al. Perfusion deficit parallels exacerbation of cerebral ischemia/reperfusion injury in hyperglycemic rats. J Cereb Blood Flow Metab 1997; 17:553-9. http://dx.doi.org/10.1097/00004647-199705000-00009

20. Duckrow RB, Beard DC, Brennan RW. Regional cerebral blood flow decreases during chronic and acute hyperglycemia. Stroke 1987; 18:528. http://dx.doi.org/10.1161/01.STR.18.1.52

21. Gisselsson L, Smith ML, Siesjo BK. Hyperglycemia and focal brain ischemia. J Cereb Blood Flow Metab 1999;19:288-97. http://dx.doi.org/10.1097/00004647-199903000-00007

22. Bayliss WM. On the local reactions of the arterial wall to changes of internal pressure. J Physiol 1902;28:220-31. http://dx.doi.org/10.1113/ jphysiol.1902.sp000911

23. Palomares SM, Cipolla MJ. Vascular protection following cerebral ischemia and reperfusion. J Neurol Neurophysio/ 2011;2011(pii):S1-004

24. Cipolla MJ, Porter JM, Osol G. High glucose concentrations dilate cerebral arteries and diminish myogenic tone through an endothelial mechanism. Stroke 1997;28:405-10. http://dx.doi.org/10.1161/01.STR.28.2.405

25. Helpern $C B$, Branch $C A$, Huang $N$ et al. Impaired autoregulation with hyperglycemia. Proc Int/ Sot Mag Reson Med 2000:8:1300.

26. Bellolio MF, Gilmore RM, Stead LG. Insulin for glycaemic control in acute ischaemic stroke. Cochrane Database Syst Rev 2011:CD005346 http://dx.doi.org/10.1002/14651858.cd005346.pub3

27. Capes SE, Hunt D, Malmberg K et al. Stress hyperglycemia and prognosis of stroke in nondiabetic and diabetic patients: a systematic overview. Stroke 2001;32:2426-32. http://dx. doi.org/10.1161/hs1001.096194

28. Béjot $Y$, Aboa-Eboulé $C$, Hervieu $M$ et al. The deleterious effect of admission hyperglycemia on survival and functional outcome in patients with intracerebralhemorrhage. Stroke 2012;43:243-5. http://dx.doi.org/10.1161/STROKEAHA.111.632950

29. Ribo M, Molina CA, Delgado $P$ et al. Hyperglycemia during ischemia rapidly accelerates brain damage in stroke patients treated with IPA. J Cereb Blood Flow Metab 2007;27:1616-22. http://dx.doi.org/10.1038/sj.jcbfm.9600460

30. Murros K, Fogelholm R, Kettunen S et al. Blood glucose, glycosylated haemoglobin, and outcome of ischemic brain infarction. J Neurol Sci 1992:111:59-64. http://dx. doi.org/10.1016/0022-510X(92)90112-X

31. Poppe AY, Majumdar SR, Jeerakathil T et al. Admission hyperglycemia predicts a worse outcome in stroke patients treated with intravenous thrombolysis. Diabetes Care 2009;32:617-22. http://dx.doi.org/10.2337/dc08-1754

32. Demchuk AM, Morgenstern LB, Krieger DW et al. Serum glucose level and diabetes predict tissue plasminogen activator-related intracerebralhemorrhage in acute ischemic stroke. Stroke 1999;30:34-9. 
http://dx.doi.org/10.1161/01.STR.30.1.34

33. Bruno A, Biller J, Adams HP Jr et al. Acute blood glucose level and outcome from ischemic stroke. Trial of ORG 10172 in Acute Stroke Treatment (TOAST) Investigators. Neurology 1999;52:280-4. http://dx.doi.org/10.1212/ WNL.52.2.280

34. Grant PS, Khalid A. A prospective, observational study of the management of hyperglycaemia in acute stroke. What is the optimum level of blood glucose at which to intervene? $\mathrm{Br} J$ Diabetes Vasc Dis 2010;10:287-91. http://dx.doi.org/10.1177/1474651410390310

35. Adams HP, del Zoppo G, Alberts MJ et al. Guidelines for the early management of adults with ischemic stroke. Circulation 2007;115:e478534. http://dx.doi.org/10.1161/CIRCULATIONAHA.107.181486

36. Pittas AG, Siegel RD, Lau J. Insulin therapy for critically ill hospitalized patients: a meta-analysis of randomized controlled trials. Arch Intern Med 2004;164:2005-11. http://dx.doi.org/10.1001/archinte.164.18.2005

37. Jauch EC, Saver JL, Adams HP et al. Guidelines for the early management of patients with acute ischemic stroke: a guideline for healthcare professionals from the American Heart Association/American Stroke
Association. Stroke 2013;44:870-47. http://dx.doi.org/10.1161/STR. Ob013e318284056a

38. European Stroke Organisation (ESO) Executive Committee, ESO Writing Committee. Guidelines for management of ischaemic stroke and transient ischaemic attack 2008. Cerebrovasc Dis 2008;25:457-07. http://dx.doi.org/10.1159/000131083

39. Rocco A, Heuschmann PU, Schellinger PD et al. Glycosylated hemoglobin $\mathrm{A} 1$ predicts risk for symptomatic hemorrhage after thrombolysis for acute stroke. Stroke 2013;44:2134-8.

http://dx.doi.org/10.1161/STROKEAHA.111.675918

40. O'Neill PA, Davies I, Fullerton KJ et al. Stress hormone and blood glucose response following acute stroke in the elderly. Stroke 1991;22:842-7. http://dx.doi.org/10.1161/01.STR.22.7.842

41. Tracey F, Crawford VLS, Lawson JT et al. Hyperglycaemia and mortality from acute stroke. Q J Med 1993;86:439-46.

42. Xing Y, Hua Y, Keep RF, Xi G. Effects of deferoxamine on brain injury after transient focal cerebral ischemia in rats with hyperglycemia. Brain Res 2009;1291:113-21. http://dx.doi.org/10.1016/j.brainres.2009. 07.032

\section{MINIMED $^{\text {Th }} 640 \mathrm{G}$ A BREAKTHROUGHSYSTEM}

MINIMED ${ }^{\text {TM }} 640 \mathrm{G}$

SYSTEM COMBINES:

ADVANCED PROTECTION

PERSONALISED CONVENIENCE IMPROVED DESIGN 